\title{
Vascular Metabolic Dysfunction and Lipotoxicity
}

\author{
H. M. MATTERN, C. D. HARDIN \\ Department of Medical Pharmacology and Physiology, University of Missouri, Columbia, MO, \\ USA
}

Received November 10, 2005

Accepted March 7, 2006

On-line available March 23, 2006

\begin{abstract}
Summary
The purpose of this study was to determine the role of lipotoxicity in vascular smooth muscle (VSM). $\mathrm{C}_{1}$-BODIPY $500 / 510 \mathrm{C}_{12}$ used to assess the ability of VSM A7r5 cells to transport long-chain fatty acids showed that lipid transport did not appear to limit metabolism. Thin layer chromatography revealed that storage of transported fatty acid occurred primarily as mono- and diglycerides and fatty acids but not as triglycerides. We used lipid-induced apoptosis as a measure of lipotoxicity and found that $1.5 \mathrm{mM}$ palmitate (6.8:1) bound to albumin resulted in a 15 -fold increase in the number of apoptotic cells compared to the control at 24 hours. This apoptosis did not seem to be due to an increase in reactive oxygen species (ROS) since VSM cells incubated in palmitate showed less ROS production than cells incubated in albumin only. Similar exposure to oleate did not significantly increase the number of apoptotic cells compared to the control. Oleate actually significantly attenuated the apoptosis induced by palmitate, suggesting that unsaturated fatty acids have a protective effect on cells undergoing palmitate-induced apoptosis. These results suggest that vascular smooth muscle is vulnerable to lipotoxicity and that this lipotoxicity may play a role in the development of atherosclerosis.
\end{abstract}

\section{Key words}

Vascular smooth muscle $\bullet$ Palmitate $\bullet$ Oleate $\bullet$ Apoptosis $\bullet$ Reactive oxygen species

\section{Introduction}

Atherosclerosis is a serious disease that is characterized by the accumulation of lipids and fibrous elements in the arteries (Lusis 2000). One of the stages of this disease involves the dedifferentiation, proliferation, and migration of smooth muscle cells from the medial layer into the intima. The smooth muscle cells accumulate and produce extracellular matrix, which forms the fibrous plaque of the lesion (Lusis 2000). In addition to proliferating, vascular smooth muscle cells in the lesion also undergo apoptosis (Beckman et al. 2002,
Geng and Libby 2002). Early in the process of atherosclerosis, lipid accumulates in the vessel wall resulting in alterations of vascular smooth muscle function, such as proliferation and apoptosis (Geng and Libby 2002).

Normal fatty acid homeostasis involves the balance between the formation or delivery of fatty acids and the utilization of fatty acids. When cells accumulate more fatty acids than are required for anabolism or catabolism, extra fatty acids are then typically stored as triglycerides (Schaffer 2003). Adipose tissue is capable of storing large amounts of fatty acid as triglycerides, but 
non-adipose tissue has a limited capacity for the storage of lipids. Lipotoxicity occurs when excess lipids accumulate in non-adipose tissues and results in cell dysfunction or apoptosis (Schaffer 2003).

Saturated fatty acids, such as palmitate, appear to contribute to lipotoxicity (Listenberger et al. 2003). For example, palmitate has been shown to induce apoptosis in a variety of tissues (Paumen et al. 1997, de Vries et al. 1997, Hardy et al. 2000, Cnop et al. 2001, Listenberger et al. 2001, Maedler et al. 2001). Palmitate is most likely able to induce apoptosis because it is metabolized into pro-apoptotic compounds such as ceramide (Dyntar et al. 2001) and reactive oxygen species (ROS) (Listenberger et al. 2001). Saturated fatty acids may also result in decreased cardiolipin synthesis, resulting in the release of cytochrome $c$ (Ostrander et al. 2001). Recent evidence suggests that lipotoxicity may occur in vascular smooth muscle. For instance, lipid and cholesterol can accumulate within vascular smooth muscle cells (Martinet et al. 2002, Batetta et al. 2003), lipid can cause a shift from the contractile phenotype to the synthetic phenotype (Massaeli et al. 1999, Suzuki et al. 2001, Aikawa et al. 2002), and apoptosis of vascular smooth muscle cells can be induced by ROS (Taniyama and Griendling 2003). Therefore, excess plasma lipid levels, such as those that occur during diabetes, obesity, and high fat diets, may be a significant contributor to vascular lipotoxicity, and ultimately atherosclerosis.

The purpose of this study was to further elucidate the role that lipotoxicity plays in vascular smooth muscle cells. In this study we used A7r5 rat aortic smooth muscle cells and hog carotid arteries to examine the uptake, storage, and effects on ROS generation and VSM cell apoptosis of the excess lipid provision to VSM cells.

\section{Methods}

\section{Tissue handling}

Hog carotid arteries were obtained from the campus abattoir and dissected free of loose fat, connective tissues, and adventitia. They were placed in physiological saline solution (PSS), $\mathrm{pH} 7.4$, preequilibrated by bubbling with a $95 \% \mathrm{O}_{2}-5 \% \mathrm{CO}_{2}$ gas mixture. PSS was composed of $116 \mathrm{mM} \mathrm{NaCl}, 4.6 \mathrm{mM}$ $\mathrm{KCl}, 1.16 \mathrm{mM} \mathrm{KH} \mathrm{PO}_{4}, 25.3 \mathrm{mM} \mathrm{NaHCO}, 2.5 \mathrm{mM}$ $\mathrm{CaCl}_{2}, 1.16 \mathrm{MgSO}_{4}, 0.85 \mathrm{mM}$ penicillin, $0.069 \mathrm{mM}$ streptomycin, and $5 \mathrm{mM}$ glucose. Arteries were stored in PSS with $5 \mathrm{mM}$ glucose at $4{ }^{\circ} \mathrm{C}$ until needed.

\section{Cell Culture}

A7r5 vascular smooth muscle cells from rat aorta (American Type Culture Collection, Manassas, VA) were grown in $75-\mathrm{cm}^{2}$ culture flasks and on Lab-Tek II chambered coverglass (Nalge Nunc International, Rochester, NY) in Dulbecco's modified Eagle's medium (DMEM, Sigma, St. Louis, MO). This contained $5.5 \mathrm{mM}$ D-glucose, $26.2 \mathrm{mM} \mathrm{NaHCO} 3,1 \mathrm{mM} \mathrm{C} \mathrm{H}_{3} \mathrm{O}_{3} \mathrm{Na}$, and $4 \mathrm{mM}$ L-glutamine. DMEM was supplemented with $10 \%$ fetal bovine serum (FBS, GIBCO, Grand Island, NY) and $1 \%$ antibiotic/antimycotic solution (Sigma). Cells were incubated in a $5 \% \mathrm{CO}_{2} /$ humidified chamber at $37{ }^{\circ} \mathrm{C}$. The media was changed every two days to avoid microbial contamination. Cells used in the apoptosis and ROS experiments were grown in $75-\mathrm{cm}^{2}$ flasks. When the cells were $\sim 80 \%$ confluent, they were incubated in $1.5 \mathrm{mM}$ palmitate or oleate conjugated to albumin (6.8:1) for various time points and apoptosis or ROS was measured. For fatty acid uptake experiments, cells were grown on chambered coverglass until they reached $\sim 95 \%$ confluence.

\section{Fatty acid uptake}

A $7 \mathrm{r} 5$ cells were serum starved for $24 \mathrm{~h}$ before the experiment. Cells were rinsed with phosphatebuffered saline (PBS) and $2 \mathrm{ml}$ of fresh serum-free media was added to the chambered coverglass. $6.25 \mu \mathrm{M}$ of $1 \mathrm{mg} / \mathrm{ml}$ of $\mathrm{C}_{1}$-BODIPY 500/510 $\mathrm{C}_{12}$ (4,4-difluoro-5methyl-4-bora-3a,4a-diaza-s-indacene-3-dodecanoic acid, Molecular Probes, Eugene, OR) was added for up to $10 \mathrm{~min}$. Images to view fatty acid uptake were depicted by confocal microscopy.

\section{Confocal microscopy and image analysis}

Laser scanning confocal microscopy was performed by using the Bio-Rad Radiance 2000 (BioRad, Hercules, CA) on an IX-70 inverted microscope (Olympus, Tokyo, Japan). The images were captured using a $60 \mathrm{X}$ water objective and transmitted to a computer with the LaserSharp 2000 program (Bio-Rad). Images were obtained by using excitation lines from an argon krypton-argon laser at $488 \mathrm{~nm}$ and an emission filter of $515 \pm 30 \mathrm{~nm}$. The transmitted light images were acquired with Nomarski using a $637-\mathrm{nm}$ red diode laser. Image acquisition was performed in the $\mathrm{x}, \mathrm{y}$, and $\mathrm{z}$ dimensions with $\mathrm{z}$ steps of $0.30 \mu \mathrm{m}$ for all fluorescence images, with $15-20 \mathrm{z}$ steps per image. Images were taken every $45 \mathrm{~s}$. The magnification (zoom), laser iris, gain, and offset parameters were optimized for the laser and were 
kept constant for each image.

MetaMorph software (Universal Imagine, Chesterfield, PA) was used for image processing after acquisition. For each image, the central z plane was taken and background noise was removed by the median filter.

\section{Triglyceride content determination}

Arteries were incubated in PSS containing $1.5 \mathrm{mM}$ oleate and/or palmitate bound to albumin (6.8:1) at $37{ }^{\circ} \mathrm{C}$ for $16 \mathrm{~h}$. Following the incubation the tissues were blotted, weighed, and frozen in liquid nitrogen for subsequent analysis of triglyceride content. Lipids were extracted by the modified Folch method for lipid extraction as described by Hamilton et al. (1992).

Thin layer chromatography (TLC) plates (Silica Gel G, $250 \mu \mathrm{m}$ ) were developed in solvent 1 (hexane: ether:glacial acetic acid $(60: 40: 1))$ to remove contaminants and heated at $100{ }^{\circ} \mathrm{C}$ for $30 \mathrm{~min}$ before use. The lipid extracts and a standard containing a mono-, di-, and triglyceride mix (40 $\mathrm{mg}$ each) (Sigma) were dissolved in chloroform to a $1 \%$ solutions. The extracts and standard solution were spotted on the TLC plate. The TLC plate was then developed in solvent 1, dried under $\mathrm{N}_{2}$ gas for $10 \mathrm{~min}$ and then developed in solvent 2 (hexane-ether-glacial acetic acid $(90: 10: 1)$ ) to $15 \mathrm{~cm}$. The TLC plate was dried for $10 \mathrm{~min}$ and then exposed to iodine vapor for 5-10 $\mathrm{min}$, which delineated the lipid spots.

\section{Apoptosis determination}

A7r5 cells were incubated in DMEM (serumfree) containing $1.5 \mathrm{mM}$ palmitate or $1.5 \mathrm{mM}$ oleate conjugated to albumin $(6.8: 1)$ or $0.22 \mathrm{mM}$ albumin with or without $0.5 \mu \mathrm{M}$ staurosporine (LC Laboratories, Woburn, MA) in DMSO for 12, 18, and $24 \mathrm{~h}$. After incubation, the media were isolated and the detached cells in the media centrifuged. Cells were harvested with 1X trypsin-EDTA solution (Sigma). The trypsinized cells were centrifuged and added to the collected detached cells. The cells were then rinsed in PBS that contained $0.5 \%(\mathrm{w} / \mathrm{v})$ BSA. After this the cells were incubated in $1 \%(\mathrm{w} / \mathrm{v})$ paraformaldehyde in PBS ( $\mathrm{pH} 7.4)$ for 1 hour on ice in the dark. Thereafter the cells were centrifuged, rinsed in PBS with $0.5 \%(\mathrm{w} / \mathrm{v}) \mathrm{BSA}$, collected, and incubated in a permeabilization solution that contained $0.1 \%(\mathrm{v} / \mathrm{v})$ Triton X-100 in $0.1 \%(\mathrm{w} / \mathrm{v})$ sodium citrate in water for two minutes on ice. The cells were then centrifuged and rinsed in wash buffer from an APO-BrdU TUNEL apoptosis kit (Phoenix Flow Systems, San
Diego, CA). The cells were incubated in a DNA labeling solution from the kit for 1 hour in a $37^{\circ} \mathrm{C}$ water bath. The cells were rinsed in a rinse buffer from the apoptosis kit, centrifuged, and resuspended in Fluorescein-PRB-1 from the kit in the dark for $30 \mathrm{~min}$ at $25{ }^{\circ} \mathrm{C}$. Propidium iodide (PI) with RNase was added to the cells and they were incubated for another $30 \mathrm{~min}$ at $25^{\circ} \mathrm{C}$ in the dark.

A FACScan flow cytometer (Becton Dickensen, San Jose, CA) with CellQuest software was used to determine the percent apoptosis. Fluorescence was collected and gated for size. Instrument settings according to the apoptosis kit from Phoenix Flow Systems were used.

\section{ROS determination}

A7r5 cells were incubated in DMEM (serumfree) containing $1.5 \mathrm{mM}$ palmitate conjugated to albumin (6.8:1) or $0.22 \mathrm{mM}$ albumin for $3,6,9,12,18$, and 24 hours. Cells were also incubated in $0.22 \mathrm{mM}$ albumin and $5 \mathrm{mM} \mathrm{H} \mathrm{H}_{2} \mathrm{O}_{2}$ for $30 \mathrm{~min}$ as a positive control. After the incubation, the media were taken off and detached cells in the media were centrifuged and resuspended in DMEM (containing $10 \%$ FBS). This solution was placed back on the attached cells for $15 \mathrm{~min}$. The detached cells were then collected and resuspended in PBS supplemented with $0.5 \mathrm{mM} \mathrm{MgCl} 2$ and $0.92 \mathrm{mM} \mathrm{CaCl}_{2}$. This solution was then returned into the flasks with the attached cells. $2 \mu \mathrm{M}$ of the ROS detector 6-carboxy-2',7'-dichlorodihydrofluorescein diacetate, di(acetoxymethyl ester) (C-2938) (Molecular Probes) was added to each flask and the cells were incubated for 1 hour at $37^{\circ} \mathrm{C}$. Detached cells were centrifuged and attached cells were harvested from the flasks with $1 \mathrm{X}$ trypsin-EDTA. The cells were then rinsed with PBS and centrifuged. After this the cells were resuspended in PI and incubated for $30 \mathrm{~min}$ at $4{ }^{\circ} \mathrm{C}$ in the dark.

A FacScan flow cytometer (Becton Dickensen) with CellQuest software was used to determine the percentage of cells with ROS. Fluorescence was collected and gated according to size and intact plasma membranes (PI negative). The change in median fluorescence over control cells was determined.

\section{Statistical analysis}

Statistics were calculated using Microsoft Excel and SigmaStat using the a one-tailed Student's $t$ test for paired samples (Figs 3, 4 and 6) and ANOVA with post hoc Tukey test (Fig. 5). $\mathrm{P} \leq 0.05$ values were considered significant. All values are expressed as mean \pm S.E.M. 


\section{A. 0 seconds}

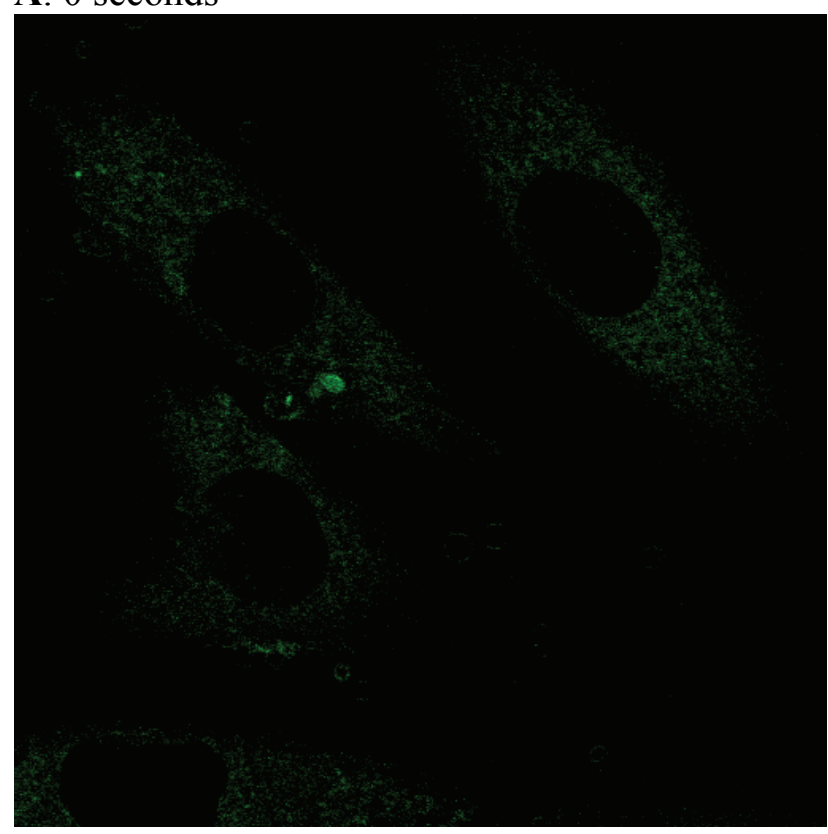

\section{90 seconds}

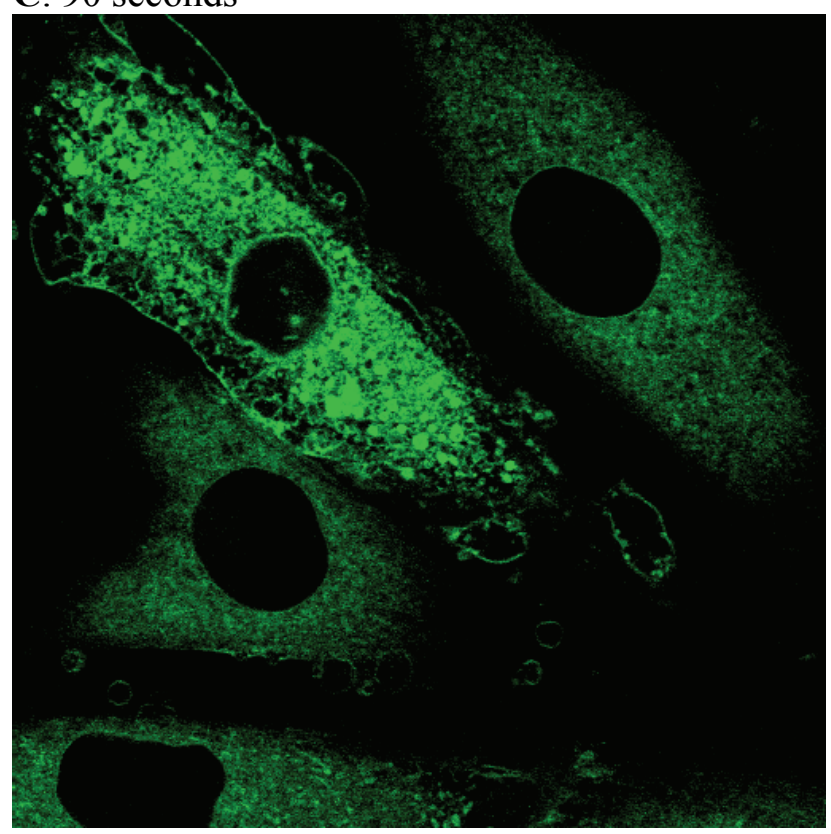

\section{B. 45 seconds}

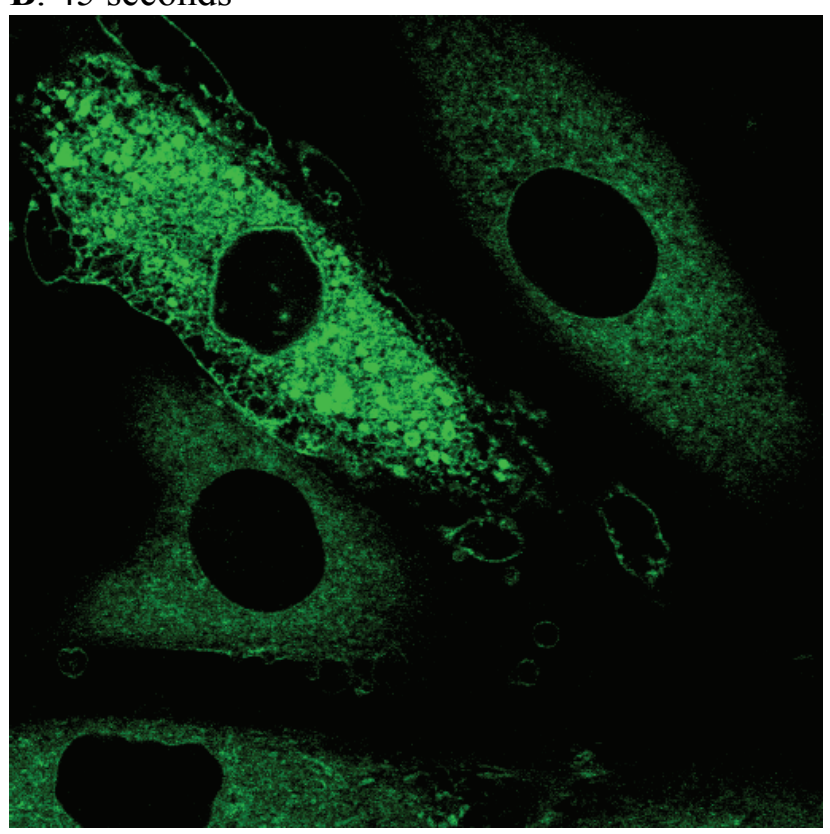

\section{405 seconds}

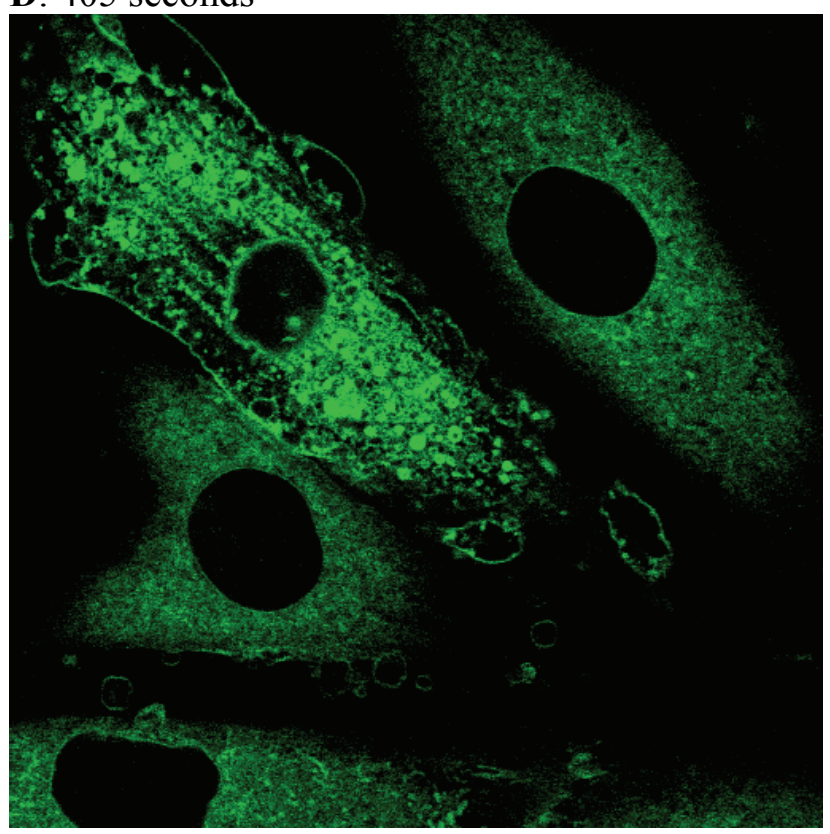

Fig. 1. Fatty acid accumulation in A7r 5 cells. Cells were serum-starved for $24 \mathrm{~h}$ and then incubated in $C_{1}-B O D I P Y-C_{12}$ for $($ A) $0,(B) 45$, (C) 90, and (D) $405 \mathrm{~s}$. Images were taken with confocal microscopy and the central $z$ plane is shown.

\section{Results}

\section{Fatty acid uptake}

Previous data show that ${ }^{13} \mathrm{C}$-labeled acetate, ${ }^{13} \mathrm{C}$-labeled glucose, and unlabeled (endogenous) substrate utilization in hog carotid arteries do not change when incubated in $0.71 \mathrm{mM}$ oleate (C18:1) as compared to control conditions. This suggests that oleic acid is not an oxidative substrate for vascular smooth muscle or that an increase in exogenous long-chain fatty acid oxidation induces a decrease in endogenous lipid oxidation, keeping the total unlabeled substrate oxidation constant (Allen and Hardin 2001). It is possible that the low oleate oxidation may be due to fatty acid transport limitations. A fluorescent long-chain fatty acid analogue, C1-BODIPY$\mathrm{C} 12$, has been used to demonstrate fatty acid transport in Saccharomyces cerevisiae (Zou et al. 2002). The length of this analog is approximately the length of a 16 carbon fatty acid and can be used to represent long chain fatty acids (Zou et al. 2002). To see if fatty acids are 


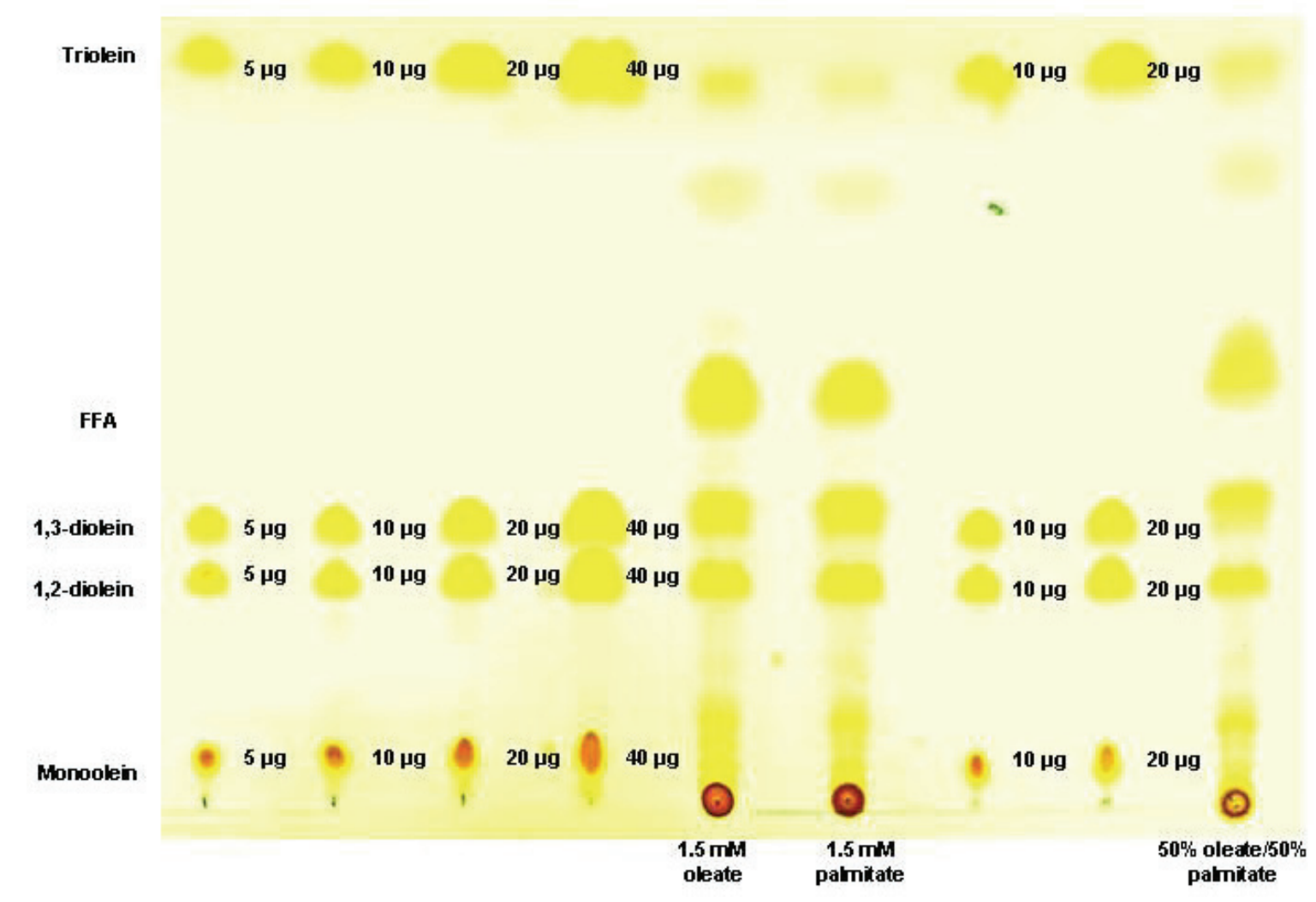

Fig. 2. TLC plate of lipid extracts of hog carotid arteries incubated in $1.5 \mathrm{mM}$ palmitate and/or oleate (bound to albumin at a molar ratio of 6.8:1) prepared by the modified Folch method. The extract spot was developed on the TLC plate along with a standard containing mono-, di-, and triglycerides. The locations of the lipids on the TLC plate are indicated. In arteries incubated in $1.5 \mathrm{mM}$ palmitate, $1.5 \mathrm{mM}$ oleate, and $50 \%$ oleate $/ 50 \%$ palmitate, there was $4.10,2.54$, and $5.91 \mu \mathrm{g}$ triolein, $31.59,25.48$, and $23.27 \mu \mathrm{g}$ free fatty acids, $14.02,18.81$, and $13.81 \mu \mathrm{g} 1,3$-diolein, $9.78,11.14$, and $8.12 \mu \mathrm{g} 1,2$ diolein, and 1.16, 1.53, and $0.11 \mu \mathrm{g}$ monolein, respectively.

transported effectively in vascular smooth muscle cells, we incubated A7r5 cells in $6.25 \mu \mathrm{M}$ C1-BODIPY-C12. The intensity, which is an indication of fatty acid accumulation, was apparent at the onset of C1-BODIPYC12 addition (Fig. 1). The rate of fatty acid uptake appeared to be greatest from 0 to 45 seconds. These results suggest that fatty acids are capable of being rapidly taken up in smooth muscle cells. Therefore, the low oleate oxidation observed in vascular smooth muscle (Allen and Hardin 2001) does not appear to be limited by fatty acid uptake.

\section{Triglyceride stores}

If the low fatty acid oxidation is not due to limitations in uptake, then it is possible that the poor oleate oxidation is the result of fatty acids that are being stored as triglycerides (TG). Substantial incorporation of oleic acid into TG stores of vascular smooth muscle cells in culture after 8, 16, and 24-h incubations has been previously described (Bergstraesser and Bates 1988). However, in the current study we found that hog carotid arteries incubated for $16 \mathrm{~h}$ in $1.5 \mathrm{mM}$ oleate and/or palmitate bound to albumin (6.8:1) exhibit a low level of incorporation into TG (Fig. 2). Thus, the low oleate oxidation is not due to storage into triglycerides. Instead of being stored as TG, palmitate and oleate were stored as monoglycerides, diglycerides, and free fatty acids.

\section{Apoptosis time course}

If fatty acids are being transported and not being stored as triglycerides, then they may be capable of causing detrimental effects to the cells. Palmitate, which is a generator of pro-apoptotic compounds such as ceramide (Dyntar et al. 2001) or reactive oxygen species (ROS) (Listenberger et al. 2001) and may decrease cardiolipin synthesis (Hardy et al. 2003, Ostrander et al. 2001), appears to induce apoptosis in different tissues (Cnop et al. 2001, de Vries et al. 1997, Hardy et al. 2000, Listenberger et al. 2001, 2003, Maedler et al. 2001, Paumen et al. 1997). We therefore examined the role that palmitate may play in apoptosis in VSM. A7r5 cells were incubated in albumin or $1.5 \mathrm{mM}$ palmitate conjugated to 


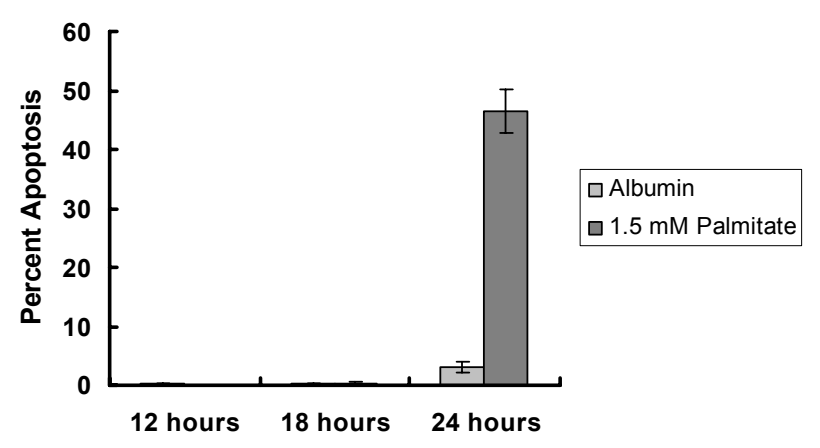

Fig. 3. Apoptosis time course for cells incubated in albumin or palmitate. A7r5 cells were incubated in albumin and $1.5 \mathrm{mM}$ palmitate for 12,18 , and 24 hours. Apoptosis was determined by flow cytometry.

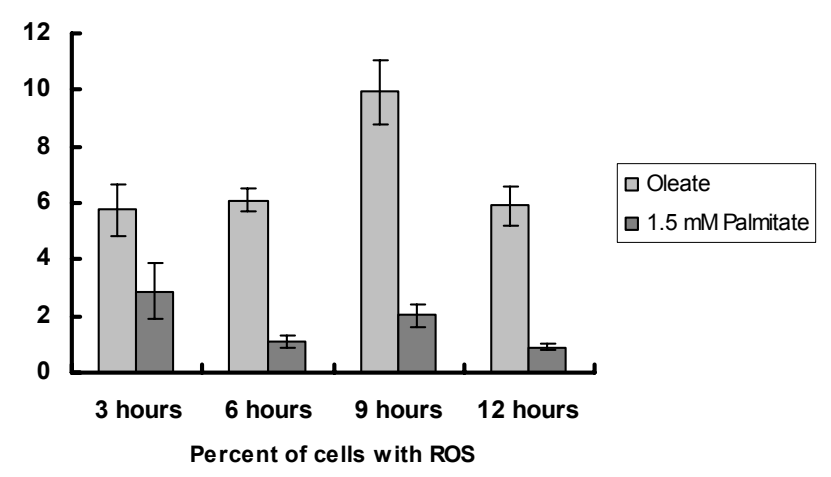

Fig. 4. The effect of palmitate on ROS production. A7r5 cells were incubated in albumin or $1.5 \mathrm{mM}$ palmitate for $3,6,9$, and 12 hours. The percentage of cells with ROS was determined by flow cytometry.

albumin for 12, 18, and $24 \mathrm{~h}$. Figure 3 shows that as the time that the cells are incubated with palmitate increases, the percentage of cells undergoing apoptosis also rises, with insignificant apoptosis in cells incubated in only albumin. At 12 and $18 \mathrm{~h}$ of incubation in palmitate, only $0.08 \pm 0.03 \% \quad(\mathrm{n}=3)$ and $0.44 \pm 0.25 \% \quad(\mathrm{n}=3)$ were apoptotic, respectively. At $24 \mathrm{~h}$, there was a significant increase in the number of cells that were apoptotic $(46.50 \pm 3.67 \%(n=3))$. These results show that palmitate induces apoptosis in a time-dependent manner. Consistent with previous studies (Listenberger et al. 2003), oleate did not induce apoptosis in smooth muscle cells (data not shown).

\section{Reactive oxygen species}

Palmitate has been shown to induce apoptosis in Chinese hamster ovary (CHO) cells by increasing ROS (Listenberger et al. 2001). To see if the apoptosis caused by palmitate was due to the production of reactive oxygen species in VSM, we incubated A7r5 cells in albumin or $1.5 \mathrm{mM}$ palmitate for $3,6,9$, and $12 \mathrm{~h}$ and measured

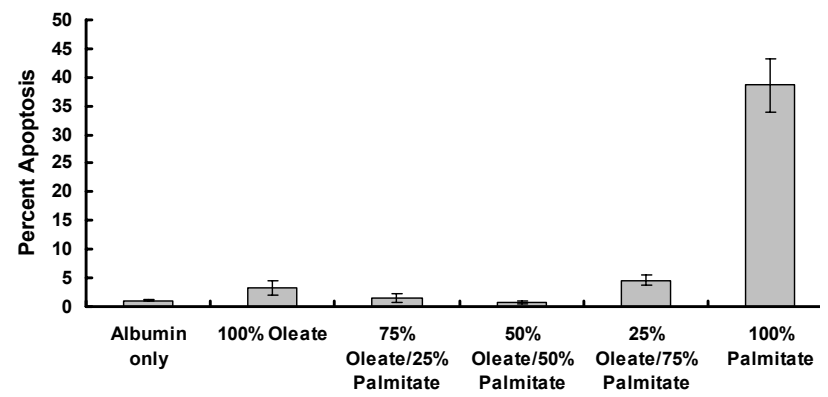

Fig. 5. The effect of varying ratios of palmitate and oleate on apoptosis. A7r5 cells were incubated in albumin, $1.5 \mathrm{mM}$ oleate, $1.5 \mathrm{mM}$ palmitate, and different ratios of $1.5 \mathrm{mM}$ oleate and 1.5 $\mathrm{mM}$ palmitate for 24 hours. Apoptosis was determined by flow cytometry.

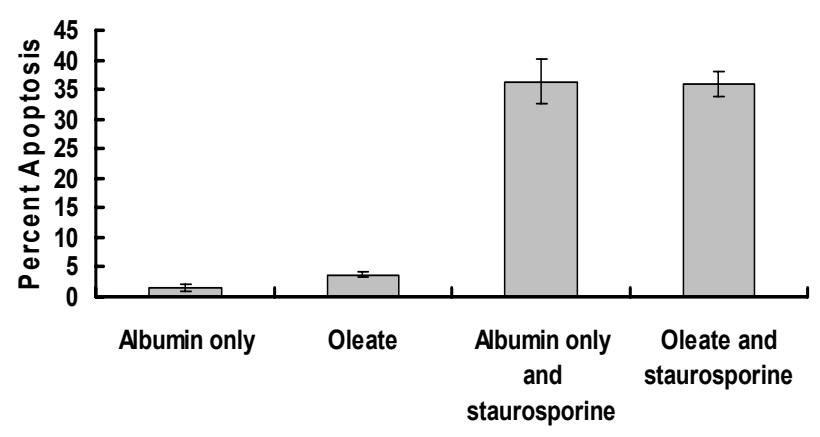

Fig. 6. The effect of oleate on staurosporine-induced apoptosis. A7r5 cells were incubated in albumin or $1.5 \mathrm{mM}$ oleate with or without $0.5 \mu \mathrm{M}$ staurosporine for 24 hours. Apoptosis was determined by flow cytometry. Values are presented as the mean \pm S.E.M.

ROS. We also incubated cells in albumin and $5 \mathrm{mM} \mathrm{H}_{2} \mathrm{O}_{2}$ for $30 \mathrm{~min}$ as a positive control. Cells incubated in $\mathrm{H}_{2} \mathrm{O}_{2}$ had a 10 -fold increase in cells containing ROS than those incubated in only albumin (data not shown). However, A $7 \mathrm{r} 5$ cells that were incubated in palmitate actually had a significantly lower percentage of cells with ROS at each time point than those cells incubated in albumin only (Fig. 4). At time points longer than $12 \mathrm{~h} \mathrm{(18} \mathrm{and} 24 \mathrm{~h})$, we did not detect any ROS because there were very few viable cells remaining (data not shown). Therefore, the apoptosis caused by palmitate in VSM is not due to an increase in ROS, but rather due to something else being produced in the cell, such as ceramide or may possibly be due to a decrease in baseline ROS production.

Protective effect of oleate on palmitate-induced apoptosis

Previous studies have demonstrated that unsaturated fatty acids such as oleate have a protective effect against apoptosis induced by palmitate in pancreatic $\beta$-cells (Cnop et al. 2001, Eitel et al. 2002) and breast cancer cells (Hardy et al. 2000). To see if oleate 
had a protective effect against apoptosis in VSM, we incubated A7r5 smooth muscle cells in different percentages of $1.5 \mathrm{mM}$ palmitate and $1.5 \mathrm{mM}$ oleate for $24 \mathrm{~h}$, and in $0.5 \mu \mathrm{M}$ staurosporine, which induces apoptosis by inhibiting kinases, with or without oleate for $24 \mathrm{~h}$. There was a significant reduction in apoptosis caused by palmitate in the cells treated with both oleate and palmitate. Among the treatment groups containing certain amounts of oleate, there were no significant differences in the incidence of apoptosis (Fig. 5). Oleate did not, however, protect against staurosporine-induced apoptosis, suggesting that palmitate and staurosporine cause apoptosis via different mechanisms (Fig. 6).

\section{Discussion}

In this study we demonstrated that the low oleate oxidation in vascular smooth muscle we previously had observed (Allen and Hardin 2001) was probably not due to a limitation in fatty acid transport or to storage of oleate as triglyceride. We also showed that, unlike oleate (C18:1), palmitate (C16:0) induced apoptosis in vascular smooth muscle. Palmitate is most likely transported into the cell effectively and not stored as triglyceride. Therefore, palmitate, which is a precursor for proapoptotic compounds such as ceramide (Dyntar et al. 2001) and reactive oxygen species (ROS) (Listenberger et al. 2001) and may cause a decrease in cardiolipin production (Hardy et al. 2003, Ostrander et al. 2001), is able to cause mitochondrial dysfunction, suggesting that lipotoxicity may play a role in vascular smooth muscle.

\section{Vascular smooth muscle fatty acid transport and storage}

It is possible that the low oxidation of oleate we previously observed (Allen and Hardin 2001) was due to either a limitation in fatty acid transport across the cell or due to oleate being stored as triglyceride, and thus rendering it less available for metabolism. By using a fluorescent fatty acid analog, which is representative of long-chain fatty acids such as oleate and palmitate, we demonstrated that fatty acids are readily taken up in vascular smooth muscle cells, similar to wild-type yeast, which is a model system for lipid uptake measurements (Zou et al. 2002). Therefore, the low rate of oxidation of oleate (Allen and Hardin 2001) is probably not due to a limitation in fatty acid transport.

We also found that oleate and palmitate are not readily stored as TG in VSM. Instead, when palmitate and oleate are added to hog carotid arteries, they occur as monoglycerides, diglycerides, and free fatty acids inside the cell. Thus, the low oleate oxidation (Allen and Hardin 2001 ) is not due to the storage of fatty acids as TG.

\section{Lipotoxicity and vascular disease}

Lipotoxicity occurs when excess lipids accumulate in non-adipose tissues leading to cell dysfunction or cell death (Schaffer 2003). Lipotoxicity has been reported in a number of cell types (de Vries et al. 1997, Paumen et al. 1997, Cnop et al. 2001, Hardy et al. 2000, Cnop et al. 2001, Maedler et al. 2001, Listenberger et al. 2001, 2003). The dyslipidemic environment that accompanies diabetes, such as increased triglyceride levels, lowered HDL levels, and increased LDL and VLDL levels (Beckman et al. 2002), may contribute to lipotoxicity. The combination of dyslipidemia and diabetes is critical for inducing atherosclerosis. For example, feeding diabetic pigs a high fat/high cholesterol diet resulted in the development of more fatty streaks, which is the first step in plaque formation, than feeding non-diabetic pigs the same diet (Dixon et al. 1999). The lipid accumulation in the vessel wall during atherosclerosis causes vascular smooth muscle cells in the vessel to dedifferentiate from a contractile phenotype to a proliferative or secretory phenotype and to migrate from the media to form the neointima (Beckman et al. 2002, Hsueh and Law 1999), where they proliferate (Suzuki et al. 2001). It has been shown that excess cholesterol is esterified and accumulates in lipid droplets within the cytoplasm of vascular smooth muscle (Batetta et al. 2003, Martinet et al. 2002). Evidence suggests that dyslipidemia promotes vascular smooth muscle phenotype change and proliferation (Aikawa et al. 2002, Massaeli et al. 1999, Suzuki et al. 2001). In addition to proliferation, vascular smooth muscle cells in the atherosclerotic lesion can also undergo apoptosis (Beckman et al. 2002, Geng and Libby 2002), which may contribute to the creation of the lipid core of the plaque. Reactive oxygen species (ROS), such as superoxide, have also been shown to induce apoptosis in vascular smooth muscle (Taniyama and Griendling 2003). This supports the lipotoxic effect of diabetic dyslipidemia, given that increased plasma free fatty acids can cause the release of superoxide from mitochondrial oxidative metabolism and an increase in superoxide production by NAD $(\mathrm{P}) \mathrm{H}$ oxidase (Taniyama and Griendling 2003). These observations suggest lipotoxicity may occur in vascular smooth muscle during atherosclerosis. 
Palmitate causes apoptosis in vascular smooth muscle cells

Several studies have demonstrated that palmitate, a saturated fatty acid, induces apoptosis in a variety of tissues (de Vries et al. 1997, Paumen et al. 1997, Hardy et al. 2000, Cnop et al. 2001, Maedler et al. 2001, Listenberger et al. 2001, 2003). However, the role that palmitate plays in vascular smooth muscle is unknown. Our study shows that palmitate causes apoptosis in vascular smooth muscle. However, oleate, an unsaturated fatty acid, did not induce apoptosis. Palmitate most likely causes apoptosis because the metabolism of palmitate, unlike oleate, results in the formation of proapoptotic compounds such as ceramide (Dyntar et al. 2001) and ROS (Listenberger et al. 2001). It has also been demonstrated in cardiomyocytes (Ostrander et al. 2001) and breast cancer cells (Hardy et al. 2003) that during palmitate-induced apoptosis there is a decrease in cardiolipin synthesis. Therefore, it is also conceivable that palmitate causes apoptosis by decreasing cardiolipin production, which is necessary for cytochrome $c$ retention. Our results demonstrate that fatty acids can readily enter VSM cells and that palmitate and oleate are not being stored as TG in VSM. Thus, the possibility exists that palmitate is transported into the cell effectively and not stored as triglycerides and it is more free to be metabolized into these pro-apoptotic compounds, ultimately resulting in apoptosis.

One of the pro-apoptotic components that can lead to apoptosis is ROS. We demonstrated that the apoptosis of VSM caused by palmitate is not due to an increase in reactive oxygen species. Instead, we observed a decrease in ROS. This is consistent with findings that show decreased ROS levels in cardiomyocytes incubated in palmitate compared to cardiomyocytes incubated in either albumin or oleate (Hickson-Bick et al. 2002). It is possible then that palmitate caused apoptosis in these cells by increasing ceramide production or decreasing cardiolipin synthesis. However, the possibility also exists that the decrease in ROS observed may be responsible for the incidence of apoptosis. For example, it is possible that ROS are necessary for smooth muscle cell survival (Irani 2000). Suppression of intracellular hydrogen peroxide has been shown to promote apoptosis in smooth muscle cells. This suggests that ROS may act as signaling intermediates in anti-apoptotic pathways in vascular smooth muscle cells (Irani 2000). Thus, in VSM cells, reactive oxygen species may play a role in keeping the cells alive. When these cells are treated with palmitate, the decrease in ROS observed may be responsible for the increase in apoptosis.

Oleate may protect cells against palmitateinduced apoptosis in VSM cells. In other cell types, oleate has been shown to protect from palmitate-induced apoptosis (Cnop et al. 2001, Eitel et al. 2002, Hardy et al. 2000). Oleate blocked palmitate-induced apoptosis in breast cancer cells by restoring cardiolipin levels (Hardy et al. 2003). Therefore, it is possible that the reduction in apoptosis in cells that were co-incubated in palmitate and oleate may be due to the stabilization of cardiolipin in the mitochondrial membrane and thus a decrease in the release of cytochrome $c$. Some studies have shown that oleate may protect cells against palmitate-induced apoptosis by shuttling palmitate into triglyceride stores (Cnop et al. 2001, Listenberger et al. 2003). However, during our triglyceride storage experiments, there was no apparent change in the amount of TG in arteries that were co-incubated in oleate and palmitate. Based on our data, oleate does not appear to protect against palmitateinduced apoptosis by preventing the inhibition of kinases involved in apoptosis.

Mitochondrial dysfunction and lipotoxicity in vascular smooth muscle

After the normal capacity for vascular smooth muscle to increase fatty acid oxidation when faced with excess lipid has been surpassed, it is proposed that a number of pathological cascades may be executed, resulting in mitochondrial dysfunction, induction of apoptosis, and changes in vascular smooth muscle phenotype and function. In a previous study from our lab, we found that hog carotid vascular smooth muscle from diabetic/dyslipidemic swine exhibited an altered pattern of mitochondrial substrate utilization which was interpreted as being indicative of mitochondrial dysfunction (Roberts et al. 2001). A similar mitochondrial dysfunction was observed in bladder smooth muscle from dyslipidemic swine (Hardin et al. 2003). In the current study, palmitate administration caused apoptosis in VSM cells and this apoptosis was not due to an increase in ROS. Therefore, we conclude that vascular smooth muscle is susceptible to lipotoxicity and at least a portion of the lipotoxicity observed may be due to effects of palmitate or other long-chain saturated fatty acids with unsaturated fatty acids possibly playing a protective role. If VSM is susceptible to saturated fatty acid induced apoptosis, then it is possible that high plasma fatty acid levels, such as that which occurs during 
diabetes and obesity, may contribute to the development of atherosclerosis.

\section{Acknowledgements}

Grant support was from NIH DK 60668. Tissues were graciously provided by Gregg Rentfrow from the Meat Sciences Department (University of Missouri-Columbia).
We thank Joyce Carafa at the Cell and Immunobiology Core Facility (University of Missouri-Columbia) for her assistance with flow cytometry, and Dr. Thomas Phillips, Dr. Mayandi Sivaguru, and Brady Hardiman at the Molecular Cytology Core for their assistance with confocal microscopy.

\section{References}

AIKAWA M, SUGIYAMA S, HILL CC, VOGLIC SJ, RABKIN E, FUKUMOTO Y, SCHOEN FJ, WITZTUM JL, LIBBY P: Lipid lowering reduces oxidative stress and endothelial cell activation in rabbit atheroma. Circulation 106: 1390-1396, 2002.

ALLEN TJ, HARDIN CD: Oleate oxidation and mitochondrial substrate selection in vascular smooth muscle. $J$ Vasc Res 38: 276-287, 2001.

BATETTA B, MULAS MF, SANNA F, PUTZOLU M, BONATESTA RR, GASPERI-CAMPANI A, RONCUZZI L, BAIOCCHI D, DESSI S: Role of cholesterol ester pathway in the control of cell cycle in human aortic smooth muscle cells. FASEB J 17: 746-748, 2003.

BECKMAN JA, CREAGER MA, LIBBY P: Diabetes and atherosclerosis: epidemiology, pathophysiology, and management.[see comment]. JAMA 287: 2570-2581, 2002.

BERGSTRAESSER LM, BATES SR: Comparison of fatty acid and triacylglycerol metabolism of macrophages and smooth muscle cells. Lipids 23: 641-646, 1988.

CNOP M, HANNAERT JC, HOORENS A, EIZIRIK DL, PIPELEERS DG: Inverse relationship between cytotoxicity of free fatty acids in pancreatic islet cells and cellular triglyceride accumulation. Diabetes 50: 1771-1777, 2001.

DE VRIES JE, VORK MM, ROEMEN TH, DE JONG YF, CLEUTJENS JP, VAN DER VUSSE GJ, VAN BILSEN M: Saturated but not mono-unsaturated fatty acids induce apoptotic cell death in neonatal rat ventricular myocytes. J Lipid Res 38: 1384-1394, 1997.

DIXON JL, STOOPS JD, PARKER JL, LAUGHLIN MH, WEISMAN GA, STUREK M: Dyslipidemia and vascular dysfunction in diabetic pigs fed an atherogenic diet. Arterioscler Thromb Vasc Biol 19: 2981-2992, 1999.

DYNTAR D, EPPENBERGER-EBERHARDT M, MAEDLER K, PRUSCHY M, EPPENBERGER HM, SPINAS GA, DONATH MY: Glucose and palmitic acid induce degeneration of myofibrils and modulate apoptosis in rat adult cardiomyocytes. Diabetes 50: 2105-2113, 2001.

EITEL K, STAIGER H, BRENDEL MD, BRANDHORST D, BRETZEL RG, HARING HU, KELLERER M: Different role of saturated and unsaturated fatty acids in beta-cell apoptosis. Biochem Biophys Res Commun 299: 853-856, 2002.

GENG YJ, LIBBY P: Progression of atheroma: a struggle between death and procreation. Arterioscler Thromb Vasc Biol. 22: 1370-1380, 2002.

HAMILTON RJ, HAMILTON S, SEWELL: Extraction of Lipids and Derivative Formation. In: Lipid Analysis: A Practical Approach. RICKWOOD D, HAMES BD (eds), Oxford University Press, Oxford, 1992, pp 13-64. HARDIN CD, KLEIBER BD, ROBERTS TM: Mitochondrial oxidative substrate selection in porcine bladder smooth muscle. J Urol 170: 2063-2066, 2003.

HARDY S, LANGELIER Y, PRENTKI M: Oleate activates phosphatidylinositol 3-kinase and promotes proliferation and reduces apoptosis of MDA-MB-231 breast cancer cells, whereas palmitate has opposite effects. Cancer Res 60: 6353-6358, 2000.

HARDY S, EL-ASSAAD W, PRZYBYTKOWSKI E, JOLY E, PRENTKI M, LANGELIER Y: Saturated fatty acidinduced apoptosis in MDA-MB-231 breast cancer cells. A role for cardiolipin. J Biol Chem 278: 31861-31870, 2003. 
HICKSON-BICK DL, SPARAGNA GC, BUJA LM, MCMILLIN JB: Palmitate-induced apoptosis in neonatal cardiomyocytes is not dependent on the generation of ROS. Am J Physiol 282: H656-H664, 2002.

HSUEH WA, LAW RE: Insulin signaling in the arterial wall. Am J Cardiol 84: 21 J-24J, 1999.

IRANI K: Oxidant signaling in vascular cell growth, death, and survival: a review of the roles of reactive oxygen species in smooth muscle and endothelial cell mitogenic and apoptotic signaling. Circ Res 87: 179-183, 2000.

LISTENBERGER LL, ORY DS, SCHAFFER JE: Palmitate-induced apoptosis can occur through a ceramideindependent pathway. J Biol Chem 276: 14890-14895, 2001.

LISTENBERGER LL, HAN X, LEWIS SE, CASES S, FARESE RV Jr., ORY DS, SCHAFFER JE: Triglyceride accumulation protects against fatty acid-induced lipotoxicity. Proc Natl Acad Sci USA 100: 3077-3082, 2003.

LUSIS AJ: Atherosclerosis. Nature 407: 233-241, 2000.

MAEDLER K, SPINAS GA, LEHMANN R, SERGEEV P, WEBER M, FONTANA A, KAISER N, DONATH MY: Glucose induces beta-cell apoptosis via upregulation of the Fas receptor in human islets. Diabetes 50: 1683$1690,2001$.

MARTINET W, SCHRIJVERS DM, DE MEYER GR, THIELEMANS J, KNAAPEN MW, HERMAN AG, KOCKX MM: Gene expression profiling of apoptosis-related genes in human atherosclerosis: upregulation of deathassociated protein kinase. Arterioscler Thromb Vasc Biol 22: 2023-2029, 2002.

MASSAELI H, HURTADO C, AUSTRIA JA, PIERCE GN: Oxidized low-density lipoprotein induces cytoskeletal disorganization in smooth muscle cells. Am J Physiol 277: H2017-H2025, 1999.

OSTRANDER DB, SPARAGNA GC, AMOSCATO AA, MCMILLIN JB, DOWHAN W: Decreased cardiolipin synthesis corresponds with cytochrome c release in palmitate-induced cardiomyocyte apoptosis. J Biol Chem 276: 38061-38067, 2001.

PAUMEN MB, ISHIDA Y, MURAMATSU M, YAMAMOTO M, HONJO T: Inhibition of carnitine palmitoyltransferase I augments sphingolipid synthesis and palmitate-induced apoptosis. J Biol Chem 272: 3324-3329, 1997.

ROBERTS TM, STUREK M, DIXON JL, HARDIN CD: Alterations in the oxidative metabolic profile in vascular smooth muscle from hyperlipidemic and diabetic swine. Mol Cell Biochem 217: 99-106, 2001.

SCHAFFER JE: Lipotoxicity: when tissues overeat. Curr Opin Lipidol. 14: 281-287, 2003.

SUZUKI LA, POOT M, GERRITY RG, BORNFELDT KE: Diabetes accelerates smooth muscle accumulation in lesions of atherosclerosis: lack of direct growth-promoting effects of high glucose levels. Diabetes 50: 851$860,2001$.

TANIYAMA Y, GRIENDLING KK: Reactive oxygen species in the vasculature: molecular and cellular mechanisms. Hypertension 42: 1075-1081, 2003.

ZOU Z, DIRUSSO CC, CTRNACTA V, BLACK PN: Fatty acid transport in Saccharomyces cerevisiae. Directed mutagenesis of FAT1 distinguishes the biochemical activities associated with Fat1p. J Biol Chem 277: 31062 $31071,2002$.

\section{Corresponding author}

C. D. Hardin, Department of Medical Pharmacology and Physiology, MA415 Medical Sciences Building, University of Missouri, Columbia, MO 65212, USA. Fax: (573) 884-4276. E-mail: hardinc@missouri.edu 